\title{
Crenças de eficácia de agentes escolares para a implementação de políticas
}

\section{educacionais}

\section{Efficacy beliefs of school agents for the implementation of educational policies}

\author{
Miguel Henrique Russo*, Roberta Gurgel Azzi** \\ * Universidade Cidade de São Paulo - UNICID, **TSC- Centro de Estudos e Pesquisas
}

\begin{abstract}
Resumo
O texto trata da subjetividade dos agentes na implementação das políticas educacionais. Tem como referências teóricas o ciclo de políticas, a análise organizacional e o constructo da autoeficácia. Entende a política como resultado da ação dos agentes, numa perspectiva de análise que se aproxima mais do real do que pensá-la exclusivamente na sua dimensão organizacionalformal. A subjetividade dos agentes expressa a apropriação que fazem dos textos das políticas, filtrada pelos seus valores, crenças e conhecimentos. O texto sugere que se criem condições e mecanismos institucionais que favoreçam o desenvolvimento da autoeficácia individual e coletiva na implementação das políticas educacionais.

Palavras-chave: Políticas educacionais, implementação, autoeficacia
\end{abstract}

\begin{abstract}
This article attends the subjectivity of agents when implementing educational policies. Its theoretical references are the politics (policies) cycle, the organizational analysis and the construct of self-efficacy. It understands politics as a result of the agent's actions, in a more real perspective whether than focusing exclusively in a formal-organizational sphere. The agent's subjectivity shows their appropriation of policies paperwork, filtering their values, knowledge and beliefs. This present text suggests conditions and institutional mechanisms that favour individual and collective self-efficacy on
\end{abstract} educational policies implementation.

Keywords: Educational policies, implementation, selfefficacy

\section{Introdução}

Este texto realiza ainterconexão (nexos) entre as políticas educacionais e a dimensão subjetiva dos agentes envolvidos na sua implementação a partir de uma reflexão que visa contribuir para responder ao desafio que é a implementação das políticas públicas de educação no âmbito das unidades escolares. Para tanto tomamos como referências de um lado o denominado ciclo de políticas, metodologia de análise das políticas educacionais proposto por Stephen Ball e Richard Bowe (BALL e BOWE, 1992), o modelo institucional de análise organizacional (SIMAN 1998) e o constructo da autoeficácia, integrante da Teoria Social Cognitiva de Albert Bandura (BANDURA, 1977, 1997).

O pressuposto básico do que se realiza no texto é o de que uma elevada crença da autoeficácia dos agentes escolares, responsáveis pela implementação das políticas educacionais na unidade escolar, para lidar com a implementação de determinada política aumentará a probabilidade de sucesso destas. Assim, o que segue é uma proposta de integrar dois fundamentos que têm origem em diferentes campos teóricos eque se aplicam ao mesmo processo de modo complementar, com o propósito de clarear como se dá a participação dos agentes na etapa de implementação das políticas de educação.

\section{Ciclo de políticas}

Dentre as várias perspectivas de estudo das políticas públicas destaca-se, no caso das políticas educacionais, a contribuição de Ball e Bowe (1992) denominada ciclo de políticas. Utilizada em diferentes contextos é um referencial teórico-analítico com especial preocupação com as etapas, ou contextos, das políticas de educação em geral e com as curriculares.

Essa abordagem destaca a natureza complexa e controversa da política educacional, enfatiza os processos micropolíticos e a ação dos profissionais que lidam com as políticas no nível local e indica a necessidade de se articularem os processos macro e micro na análise de políticas educacionais. (MAINARDES, 2006, p. 49)

Para Ball e Bowe (1992), as políticas públicas apresentam etapas que caracterizam momentos específicos e que compõem um ciclo completo do seu processo. Segundo aqueles autores compõem o ciclo: contexto da influência; contexto da produção de texto; contexto da prática; contexto dos resultados/efeitos; e, contexto de estratégia política. Cada uma dessas etapas tem espaços próprios e grupos de interesse específicos, mas não ocorrem de maneira sequencial e linear.

Sem prejuízo da importância das demais etapas do ciclo a implementação das políticas, no contexto da prática, é aquela que dá materialidade às concepções teóricas que permeiam as intenções dos formuladores e às finalidades estabelecidas nas etapas da influência e da produção de texto. Tanto assim que, para Ball e Bowe (1992), as análises de políticas deveriam ter foco na etapa de formação do discurso e na apropriação que os profissionais envolvidos na implementação fazem daquele, ou seja, qual a leitura que os agentes da prática 
fazem dos textos da política e como objetivam suas apropriações.

Como se pode apreender, na etapa de implementação manifesta-se a subjetividade dos agentes já que a apropriação que fazem dos textos das políticas é filtrada pelos valores, crenças e conhecimentos que trazem do processo de vida e de formação.Nesse processo revelamse as identificações e concordâncias com as propostas das políticas, bem como as discordâncias e recusas em relação às mesmas, ou seja, os agentes da prática têm uma participação ativa no processo de implementação influenciando o resultado final. O estudo da etapa de implementação revela sua complexidadee importância como parte das análises de políticas educacionais porque se refere ao espaço da organização escolar, no qual se estabelece, de fato, o quanto as políticas,ali, mantêm do proposto na sua concepção e nos textos sobre ela produzidos e como elas se apresentarão para os usuários da escola. Em outras palavras, é na prática escolar que se poderá constatar o quanto as políticas se impõem nas transformações ou quanto foram alteradas no processo de implementação pela interpretação e recriação dos agentes escolares.

Siman (1998), ao refletir sobre a análise organizacional e a análise de políticas públicas, dois referenciais que quando correlacionados ajudam na compreensão da realidade social, aponta as dificuldades enfrentadas no processo de implementação de políticas sociais. A autora articula aqueles dois planos de análise para seu intento de discussão teórica daquele tema que, segundo ela, "tem dado grande ênfase aos processos de tomada de decisões e aos fatores que influenciam esse processo, à formulação e à avaliação das políticas" (p. 128), oquepouco colabora para explicar a execução das políticas no âmbito das organizações implementadoras.

Sobre a etapa de implementação das políticas Siman destaca que sua consecução, ou não, depende da maquinaria administrativa que responde pelo processo e de outros fatores que concorrem para isso na agência responsável.Com essa perspectiva refere-se ao modelo de análise da implementação (Pressman e Wildavsky, 1979) que analisa como o processo de tradução dos objetivos políticos feito pelas agências pode provocar distorções em decorrência do grande número de sanções e vetos aos quais a implementação desses objetivos está sujeita na extensa, complexa e fragmentada rede de instâncias e níveis de deliberação.

É no interior das organizações executoras que as políticas são objetivadas, ou seja, são transformadas nas ações concretas que produzirãoseuêxito ou fracasso. Para além das etapas de concepção pelos reformadores, tomadores de decisão, as políticas são construídas pelos implementadores que podem influenciar o processo de execução e, assim, produzir distorções no resultado. Nesse sentido, a apropriação da política pública pelos seus agentes pode ser influenciada pela origem da política, seu histórico, seus apoiadores, seu conteúdo, pela clareza ou ambiguidade das metas, etc. Outra dimensão neste mesmo campo é o quanto as mudanças propostas pelas políticas alteram as rotinas cotidianas que se ligam à cultura organizacional compartilhada pelos implementadores, ou mesmoquanto elas se opõem às normas da organização e aos interesses funcionais daqueles.

Como se podeinferir do acima, os implementadores podem adquirir um elevado grau de seletividade para determinar os rumos que tomam as políticas públicas em função da apropriação que delas fazem.Ora, parece, assim, que uma melhor compreensão e análise das políticas públicas deve levar em conta e até mesmo colocar focona etapa de implementação. Esta, como se dá no interior das organizações executoras, implica e se beneficia da análise organizacional como instrumento metodológico adequado para aquele fim.

\section{Análise organizacional}

Ao tratar da análise organizacional Siman (1998) apresenta duas perspectivas concorrentes como as principais abordagens para realizar aquela análise de modo a melhor compreender a etapa de implementação das políticas públicas. Segundo a autora,

o ponto de partida da análise organizacional é o tipo ideal da burocracia weberiano, que concebe as organizações como estruturas criadas intencionalmente para atingirem metas ou intenções de algum ator (p. 130)

Para Siman (1998) o modelo institucional apresenta-se como uma alternativa na análise das organizações responsáveis pela implementação de políticas, na medida em que dá conta de mostrar que as coisas não são como se apresentam. Para ilustrar sua afirmação transcreve passagem do texto de Perrow (1978):

A explicação do comportamento organizacional não é fundamentalmente a estrutura formal da organização, os anúncios de metas e propostas, ou "outputs" de bens e serviços. Ela se encontra também na miríade de processos submersos de grupos informais, de conflitos de grupos, no recrutamento político, na dependência de grupos externos e eleitorado, na luta por prestígio, nos valores comunitários, na estrutura de poder da comunidade local e nas instituições legais. (p. 176)

Como se infere do trecho acima citado, há um quadro de variáveis organizacionais que podem ser tanto propulsoras quanto restritivas a que os objetivos se realizem. Uma adequada compreensão das organizações requer, então, a análise do quadro daquelas variáveis. A análise institucional põe peso nos valores e crenças existentes para revelar como os objetivos pretendidos pelas políticas públicas são enfraquecidos ou subvertidos pelos processos organizacionais, especialmente naqueles onde se manifestam interesses de grupo.

A escola sociológica de análise institucional trouxe uma importante contribuição para o entendimento da implementação da política pública ao enfatizar a estrutura social da organização e considerar o ambiente social como variável independente. Isto significa que por vezes os objetivos, os valores e a estrutura das organizações podem ser entendidos como variáveis dependentes.As relações formais nas organizações coordenam os papeis e as ações que lhes correspondem e não as pessoas. Estas não aceitam passivamente a condição de objeto manipulável, têm suas próprias 
vontades e necessidades que em conflito com as disposições formais podem miná-las. Põe, assim, em cheque os limites da racionalidade do comportamento humano e organizacional, pretendida pelo modelo burocrático. (cf. SIMAN, 1998)

\section{A etapa de implementação das políticas públicas e as crenças de eficácia}

O modelo institucional de análise organizacional se revela uma alternativa adequada para os estudos da etapa de implementação das políticas públicas na medida em que ela se dá no âmbito das organizações e constituem processos nos quais se manifestam variáveis típicas daqueles ambientes e que, como vimos, podem ser determinantes dos resultados daquela etapa.

Por mais que atendam necessidades concretas, reconhecidas, apoiadas pela sociedade e que acatem as exigências técnicas, as políticas públicas tendem ao insucesso se ocorrerem obstáculos na etapa de sua implementação como, por exemplo: a inexistência de pessoal capacitado para a execução das atividades que objetivam as políticas públicas; ou, as atitudes negativas dos agentes de implementação em relação à política, ao alvo da política, ou a ambos.

Em síntese, parece claro que para além dos melhoramentosdas estruturas e dos procedimentos administrativos a implementação de políticas públicas necessita incorporar as dimensões da política, inerentes de projetos sociais, e a da subjetividade dos agentes da etapa de implementação. Neste último caso o que se procura é entender a perspectiva dos atores organizacionais observando os fatores que concorrem para o sucesso ou o fracasso da implementação da política, ou seja, como os atores interpretam e traduzem os objetivos e procuram contribuir com as metas organizacionais por meio do seu envolvimento, compromisso e trabalho.

A Psicologia vem, há tempos, desenvolvendo explicações e modelos para a compreensão do comprometimento dos agentes com a organização em que aspectos subjetivos ficam em evidência. Siqueira e Gomide Junior (2004), em capítulo sobre o vínculo das pessoas com o trabalho e a organização mostram que o tema vem sendo abordado por várias disciplinas da área de Ciências Humanas, no caso, mostram o vínculo da Psicologia, Sociologia e Filosofia. No presente texto a discussão será feita a partir de um referencial específico da Psicologia denominado Teoria Social Cognitiva TSC, e toma-se o desafio de problematizar o comprometimento organizacional de um tipo determinado de organização, a escola.

A TSC é uma perspectiva em psicologia formulada por Albert Bandura (BANDURA, 1986) que postula a agência humana como princípio integrativo dos processos e mecanismos por ela explicitados (AZZI, 2017, prelo). A agência humana é compreendida como o exercício intencional da ação, por sua vez determinada pela interação recíproca entre fatores pessoais, ambientais e comportamentais (BANDURA, 2011). Para este autor, três são os tipos de agência:pessoal; delegada; e coletiva. A agência pessoal e a delegada diferenciam- se na condição de controle sobre as condições sociais e práticas institucionais que afetam o dia a dia das pessoas. A ação direta é exercida pela agência pessoal e a delegada pela mediação de outros em direção à ação esperada, afinal, não é possível que as pessoas tenham condições reais de interferir em todas as esferas de atuação que afetam seu cotidiano. A agência coletiva refere-se ao esforço coletivo para o exercício de ações, é o caso de times, equipes de trabalho e outras situações em que a ação coletiva é necessária para o atingimento de determinados resultados (BANDURA, 2001).

Segundo Bandura (2011) as crenças de eficácia funcionam como o coração da agência, ou seja, tendemos a agir em direção ao que acreditamos ter algum controle para chegar à realização. As crenças de eficácia referemse às percepções do indivíduo sobre sua capacidade para organizar e executar cursos de ação requeridos para alcançar determinados tipos de desempenho (BANDURA, 1997, p.3).Não se trata de conhecimento ou habilidade, e sim da crença de que se pode atuar em direção a determinados objetivos. Estudos tem mostrado que as crenças de eficácia têm papel preditor de ação, ou seja, tendemos a agir em consonância com o que acreditamos termos condições de organizar e executar em direção a determinados tipos de desempenho (BANDURA, 1997).

Ainda segundo Bandura (1997), crenças de eficácia são de domínio específico e são formadas principalmente a partir de quatro fontes: as experiências diretas (de maneira geral, sucessos fortalecem a crença e fracassos a enfraquecem, mas há situações diferenciadoras), as experiências vicárias, a persuasão social e os estados físicos e emocionais. As crenças são dinâmicas e específicas revelando que nossos julgamentos podem mudar em função de mudanças na situação avaliada ou nas referências pessoais de quem faz a avaliação. Ao fazermos avaliações de crenças levamos em conta elementos formulados por outras teorias da psicologia e que são a ela relacionados (mas não se confundem com a crença de eficácia) no momento de consideração da avaliação de crença, os objetivos, as expectativas de resultados e as atribuições de causalidade. As crenças de eficácia, como crenças de controle no manejo de situações emdireção a determinadas metas e cenários afetam nossos processos de escolha, persistência, motivação e processos afetivos. A literatura sobre autoeficácia tem frequentemente utilizado escalas do tipo Likert para medir percepções de autoeficácia, com assertivas do tipo 'Tenho confiança que implementarei a nova diretriz de processo de arquivamento digital no prazo solicitado', com opções de indicação que podem variar entre concordo totalmente a discordo totalmente.

Imaginemos uma situação hipotética em que a crença de alguém para implementar ou atuar na implementação de determinada política pública, quando avaliada do ponto de vista da crença, tivesse se revelado baixa. Este resultado pode estar ligado a vários aspectos, por exemplo: percepções de que não há apoio suficiente para a implementação daquela política específica; que os resultados esperados parecem estar além do que as condições existentes possibilitariam; que os recursos pessoais para o uso de determinada tecnologia 
demandariam treinamento com o material etc. Enfim, múltiplos aspectos poderiam estar compondo o cenário que avaliado levaria determinada pessoa a perceber-se com baixo senso de eficácia para a implementação daquela política.

Não é o caso de maior detalhamento sobre a autoeficácia neste momento pois o objetivo deste trabalho é marcar a possibilidade, e necessidade, de inclusão do olhar da psicologia, no caso da TSC, para uma completa compreensão dos processos envolvidos na fase de implementação de políticas do ciclo de políticas formulado por Ball e Bowe (1992).

\section{A implementação das políticas educacionais nas escolas}

Quando a análise do processo até aqui relatado se refere às políticas públicas de educação os desafios terão um lócus específico, uma organização particular, a escola. Esta, como organização, possui especificidadespróprias que a diferenciam das organizações típicas do capitalismo, ou seja, aquelas que visam a produção de mercadorias e que orientam suas atividades com vistas a acumulação do capital. Esta especificidade, que decorre da natureza do seu processo de produção pedagógico, impõe que se considere a natureza não material da transformação produzida pelo trabalho escolar e como isso determina a inserção dos agentes escolares.

A análise da implementação das políticas educacionais com o uso do modelo institucional significa reconhecer que o modelo burocrático, que supõe ser possível o controle de todas as variáveis e com isso garantir o sucesso da implementação das políticas e dos programas, possui limites quando se defronta com as imposições do real. Uma dimensão desses limites decorre da participação dos agentes escolares e das limitações da racionalidade que eles incluem nesses processos. Em outras palavras, introduz-se aí a dimensão subjetiva no processo de implementação das políticas de educação na escola.

O pressuposto do modelo burocrático é o da imparcialidade, da neutralidade, dos agentes da implementação das políticas educacionais que têm, então, suas ações determinadas pelas normas legais e funcionais. Assim, estes não têm reconhecidos os seus interesses e valores, bem como seu saber implícito sobre o campo da educação e das suas políticas.

A realidade é pródiga nos exemplos de insucesso, total ou parcial, das políticas educacionais que, assim, comprovam a necessidade de reconhecer a importância da participação dos agentes executores, que na escola incluem docentes, gestores (dirigentes, coordenadores, supervisores), trabalhadores de apoio e membros dos segmentos dos usuários. $\mathrm{O}$ fracasso na educação e na implementação das políticas do setor colocam em evidência o sujeito e sua subjetividade, excluídos do modelo burocrático de análise organizacional e do seu discurso. Esse quadro revela a importância e a necessidade de pensar formas de administração escolar que ponham os agentes e sua subjetividade, aqui discutida pelas crenças de eficácia, entre os fatores determinantes dos resultados educacionais.

A questão central deste texto é introduzir na análise das políticas educacionais a dimensão da subjetividade dos agentes na etapa de implementação que, como já vimos anteriormente, tem na necessária e indispensável participação daqueles uma fonte de imprevisibilidade quanto aos resultados da política. Não se trata, assim, de pensar a política educacional exclusivamente na sua dimensão organizacional-formal ou sob o aspecto da sua normatividade, mas de introduzir na análise de política uma dimensão que reflita o processo escolar como resultado da ação de todos os seus agentes. Essa perspectiva de análise é a que se aproxima mais da dimensão do real.

Fundamentada em evidências empíricas a teoria prediz que agentes com elevada autoeficácia e garantidas as condições de conhecimento, recursos etc. têm aumentada a probabilidade de realizar com sucesso suas ações, ou seja, têm aumentada a probabilidade de atingir com sucesso os objetivos por eles buscados.

A identificação com os fundamentos, finalidades, metas e objetivos das políticas educacionais, associados a valores e crenças dos agentes poderá contribuir para o desenvolvimento, ou elevação, da percepção de autoeficácia e, consequentemente, a probabilidade de as contribuições daqueles (professores e demais agentes do processo escolar) realizarem com sucesso a implementação das políticas educacionais no espaço escolar, o que corresponde à objetivação das ideias que presidiram sua concepção e sua formulação legal e textual.

\section{Considerações finais}

As explicações do sucesso ou do fracasso das políticas públicas, que em geral são encontradas nos modelos teóricos, ora enfatizam o processo decisório, que implica desde a formação da agenda até a formulação, ora enfatizam o processo avaliativo, que pode ser de processo ou de resultado. Em ambos os casos o que se visa é a identificação de fatores que são propulsores ou restritivos à efetividade da política. Este estudo adotou como hipótese o entendimento de que a ampla compreensão do processo das políticas públicas somente se torna viável quando se leva em conta a etapa de implementação, posto que é nela que concretamente se manifestam seus condicionantes e efeitos.

Sintetizando, a conjugação entre a identificação dos agentes executores com as políticas públicaseuma elevada crença de autoeficácia para sua implementação cria um cenário promissor para que a implementação daquelas se realize de modo favorável e que, assim, se objetivem.O insucesso que se observa na implementação de algumas políticas se deve ao fato de que muitos fatores da realidade educacional e escolar se opõem a que se alcance a conjugação daquelas condições.

É fundamental que na prática escolar se criem condições e mecanismos institucionais que favoreçam o desenvolvimento da autoeficácia individual e coletiva. Entende-se por mecanismos institucionais os princípios, as diretrizes, as normas, as estratégias e instrumentos que 
orientam o processo de implementação. Quando os mecanismos de implementação das políticas de educação são definidos sem levar em consideração a capacidade operacional dos executores, a possibilidade de que venham a ter a eficácia necessária para que a política possa ser executada tal como idealizada é praticamente nula.

Para isso podem contribuir os gestores escolares reforçando as ações bem-sucedidas dos docentes e oferecendo exemplos nos quais estes podem encontrar motivação para desenvolver e fortalecer suas crenças de eficácia pessoal e coletiva.

\section{Referências}

Azzi, R.G. (2017). Considerações sobre agência humana na obra de Bandura e inserção do assunto em periódicos brasileiros de psicologia. Em. Teoria Social Cognitiva: diversos enfoques. Bandura, A, Azzi, R. G. (Orgs). Campinas, Mercado das Letras.

Bandura, A. (1977). Self-efficacy: Toward a unifying theory of behavioral change. Psychological Review, 84, 191-215.

Bandura, A. (1986). Social foundations of thought and action: A social cognitive theory. Englewood Cliffs, NJ: Prentice-Hall.

Bandura, A. (1997). Self-efficacy: The exercise of control. New York: Freeman.

Bandura, A. (2001). Social cognitive theory: An agentic perspective. Annual review of psychology (Vol. 52, pp. 1-26). Palo Alto: Annual Reviews, Inc..

Bandura, A. (2011). Social cognitive theory. In P.A.M. van Lange, A.W. Kruglanski, \& E.T. Higgins (Eds.). Handbook of social psychological theories. (pp. 349373). London: Sage.

Mainardes, J. (2006) Abordagem do ciclo de políticas: uma contribuição para análise de políticas educacionais. Educação \& Sociedade, Campinas, v. 27, n. 94 , p. 47-69.

Perrow, C. (1978). Complex organizations: a critical essay. Dallas:Foresman and Company.

Pressman, J. L.\& Wildavsky, A. (1979). Implementation. Berkeley: University of California Press.

Siman, A. M. (1998). Análise organizacional e políticas públicas: uma breve reflexão teórica. Caderno de Filosofia e Ciências Humanas, Belo Horizonte, v. 6, n. 11, p. 128-135.

(2005). Políticas públicas: a implementação como objeto de reflexão teórica e como desafio prático. (Tese de doutorado). Universidade Federal de Minas Gerais.

http://www.dominiopublico.gov.br/pesquisa/DetalheO braForm.do?select_action $=\&$ co_obra $=32651$

Siqueira, M. M. M., Gomide Junior, S. (2004). Vínculos do indivíduo com o trabalho e com a organização. Em Psicologia, Organizações e Trabalho no Brasil. Zanelli, J. C., Borges-Andrade, J. E., Bastos, A. V. B.. Porto Alegre:ARTMED. 